\title{
Co-benefits of including CCS projects in the CDM in India's power sector
}

R. Eto ${ }^{1}$, A. Murata ${ }^{2}$, Y. Uchiyama ${ }^{1}$ and K. Okajima ${ }^{1}$

1. Department of Risk Engineering, Faculty of Systems and Information Engineering University of Tsukuba, Ibaraki, Japan

2. National Institute of Advanced Industrial Science and Technology (AIST)

Tel/Fax:+81-298-53-5134

e-mail: r0820570@risk.tsukuba.ac.jp

\begin{abstract}
:
This study examines the effects of the inclusion of the co-benefits on the potential installed capacity of carbon dioxide capture and storage (CCS) projects with a linear programming model by the clean development mechanism (CDM) in India $\hat{Q}$ power sector. It is investigated how different marginal damage costs of air pollutants affect the potential installed capacity of CCS projects in the CDM with a scenario analysis. Three results are found from this analysis. First, large quantity of IGCC with CCS becomes realizable when the certified emission reduction (CER) prices are above US\$56/tCO $\mathrm{CO}_{2}$ in the integrated Northern, Eastern, Western, and North-Eastern regional grids (NEWNE) and above US $\$ 49 / \mathrm{tCO}_{2}$ in the Southern grid. Second, including co-benefits contributes to decrease $\mathrm{CO}_{2}$ emissions and air pollutants with introduction of IGCC with CCS in the $\mathrm{CDM}$ at lower CER prices. Third, the effects of the co-benefits are limited in the case of CCS because CCS reduces larger amount of $\mathrm{CO}_{2}$ emissions than that of air pollutants. Total marginal damage costs of air pollutants of US\$250/t and US\$200/t lead to CER prices of US $\$ 1 / \mathrm{tCO}_{2}$ reduction in the NEWNE grid and the Southern grid.
\end{abstract}

Key words: Carbon dioxide capture and storage, Clean development mechanism, Co-benefit 


\section{Introduction}

Climate change is one of the biggest environmental problems and emerging countries increasingly become responsible for the problem. For a country like India, moving away from coal till 2030 is not a viable solution given the country $\hat{Q}$ GDP growth aspirations and the time taken for new technologies to be researched and made commercially available (Gosh, 2010). As a result, $\mathrm{CO}_{2}$ emissions from Indiâิ power sector are anticipated to grow inevitably in the future.

Carbon dioxide capture and storage (CCS) is a process consisting of the separation of $\mathrm{CO}_{2}$ from industrial and energy-related sources, transport to a storage location and long-term isolation from the atmosphere. (IPCC, 2005). However, there is little prospect for CCS on a commercial basis in India over the next 10-15 years (Shackley and Verma, 2008). Government of India has not introduced any policies or legislation dedicated to encouraging the development of CCS (Condor et al., 2011). According to Roman (2011), India has excluded CCS from its official mitigation scenarios because any investment in CCS will cause a price increase that is politically untenable.

India can overcome the technological and financial constraints through the Clean Development Mechanism (CDM). CDM is part of the carbon market and aims to achieve both sustainable development in developing countries and cost-effective 
reduction of greenhouse gasses (GHG) in developed countries included in the Kyoto Protocol. An important feature about a CDM project is the additionality. It is required generally that internal rate of return (IRR) of the project exceeds a specified threshold value only with the help of the revenue from the sales of the certified emission reductions (CERs). Linking CCS with the CDM is necessary before India can support the inclusion of the CCS in order to mitigate $\mathrm{CO}_{2}$ emissions at an early stage (Shackley and Verma, 2008; Condor et al., 2011). For example, Bakker et al. (2010) discuss solving the barriers of including CCS projects in the CDM. However, cost estimates for $\mathrm{CCS}$ in the power sector are generally above $\mathrm{US} \$ 40 / \mathrm{tCO}_{2}$ and current $\mathrm{CO}_{2}$ prices in the $\mathrm{CDM}$ are too low for deployment of CCS in the power sector.

Actions in pursuit of air pollution, climate change and other goals are often mutually supportive: improving energy efficiency, for example, reduces fossil-fuel consumption, reduces air pollution and greenhouse-gas emissions and benefits human health, which are termed ñco-benefitsò (IEA, 2008). CCS process itself reduces some of air pollutants as a process by-product in addition to the equipment of desulfurization systems $\left(\mathrm{DeSO}_{\mathrm{x}}\right)$ and $\mathrm{NO}_{\mathrm{x}}$ removal systems $\left(\mathrm{DeNO}_{\mathrm{x}}\right)$ technologies. The $\mathrm{NO}_{2}$ and $\mathrm{SO}_{\mathrm{x}}$ in the flue gases will be captured by the solvents that will be used to remove the $\mathrm{CO}_{2} \cdot \mathrm{NO}_{2}$ is approximately $5-10 \%$ of $\mathrm{NO}_{\mathrm{x}}$ in the flue gases, therefore, in the case of Europe, CCS contributes to a decrease for $\mathrm{SO}_{\mathrm{x}}$, however, may result in higher $\mathrm{NO}_{\mathrm{x}}$ emissions per 
$\mathrm{kWh}$ due to decreased efficiency (Tzimas et al., 2007; Koornneef et al., 2009; Koornneef et al., 2010; EEA, 2011). This is due to the fact that Europe has achieved low $\mathrm{SO}_{\mathrm{x}}$ and $\mathrm{NO}_{\mathrm{x}}$ emission levels in compliance with the Large Combustion Plant Directive. Pittela and Rübbelkeb (2008) suggest that co-benefits of climate change are higher in developing countries. It is expected that replacing exiting power technologies with CCS will reduce $\mathrm{SO}_{\mathrm{x}}$ and $\mathrm{NO}_{\mathrm{x}}$ emissions substantially in developing countries such as India which do not require power sectors to reduce $\mathrm{SO}_{\mathrm{x}}$ and $\mathrm{NO}_{\mathrm{x}}$ emissions and to equip $\mathrm{DeSO}_{\mathrm{x}}$ and $\mathrm{DeNO}_{\mathrm{x}}$ technologies. The inclusion of co-benefits will lower the threshold for transfers related to the CDM and has impacts on the cost effectiveness of CCS projects in the CDM.

This study investigates the affects of the inclusion of co-benefits on potential of CCS projects in the CDM. We develop a linear programming (LP) model of two grids, integrated Northern, Eastern, Western, and North-Eastern regional grids (NEWNE) and Southern grid in India to estimate the optimized quantity under different CER prices for two power grids up to 2031 considering the base year 2006. First, this study evaluates the potential capacity of the CCS projects in the CDM starting from 2021 in India $\hat{Q}$ power sector. Second, cumulative emissions of $\mathrm{CO}_{2}$ and air pollutants; and emission reduction benefits are estimated under different CERs and the marginal damage costs of the air pollutants with a scenario analysis. Lastly, we clarify the relationship between 
CER prices and the marginal damage costs of air pollutants.

2. Power generation mix linear programming model

This paper analyzes Indiâ̂ power generation mix by developing an LP model using General Algebraic Modeling System (GAMS) to assess the potential capacity of the CCS projects in the CDM with co-benefits. Pittela and Rübbelkeb (2008) and Nemet et al. (2010) survey studies of co-benefits. Since developing countries are not obliged to reduce GHG emissions, studies in evaluating the impacts of co-benefits of GHG mitigation are lacking (Shrestha and Pradhan, 2010). While Chen et al. (2011), Zhang et al. (2012a), and Zhang et al. (2012b) reveal the critical effects of CCS up to 2050 to mitigate $\mathrm{CO}_{2}$ emissions substantially with an LP model in China, these studies do not consider the aspects of co-benefits and CDM. Shrestha and Pradhan (2010) and Mondal et al. (2010) examine co-benefits using a MARKet Allocation (MARKAL) model in the power sector of developing countries. Although these studies discuss the future possibility of the implementation of the $\mathrm{CDM}$ through the obtained results from $\mathrm{CO}_{2}$ prices, they leave additionality out of consideration. Murata and Endo (2010) develop the model to evaluate the CDM potential of advanced power generation technologies in consideration of the additionality condition of CDM activities in China. This study only 
includes air pollutants as emission constraints and does not clarify the affects of the inclusion of the co-benefits on potential of power generation technologies.

The model we develop outputs optimized power capacities and generating electricity; technology installation period, and system costs. The model is suitable for a quantitative assessment of energy technology under different economic, social, political, and technical development assumptions. The power generation system of the base year is given to represent the base year. Efficiencies, costs, availability, capacity factors, and constraints of the power generation technology are specified. The reference energy system is the structural backbone of the model. The objective function is to maximize profit of the power sector with satisfying future final power demand given exogenously. The system costs consist of investment costs; and variable operation and maintenance $(\mathrm{O \& M})$ costs. Moreover, the costs of the primary energy consumption are added for fossil-fired power generation. The objective function to estimate the baseline and potential of the CDM projects including co-benefits is expressed as equations (1) and (2) respectively

$$
\max \pi=\sum_{j} \sum_{s} \sum_{h} Y_{j, s, h} \times\left(o g p-f_{j, s} \times \varepsilon_{j}-v_{j}\right) /(1+r)^{s-1}-\sum_{j} \sum_{s} X_{j, s} \times i n v_{j} \times c r f f_{s} /(1+r)^{s-1}
$$




$$
\begin{aligned}
& \max \pi=\sum_{j} \sum_{s} \sum_{h} Y_{j, s, h} \times\left(o g p-f_{j, s} \times \varepsilon_{j}-v_{j}\right) /(1+r)^{s-1}-\sum_{s} \sum_{j} X_{j, s} \times i n v_{j} \times c r f s /(1+r)^{s-1}+ \\
& \sum_{s} \text { QCER }_{s} \times(1-\text { share }) \times p c e r /(1+r)^{s-1}+\sum_{s}\left(\operatorname{csox} \times \operatorname{SOX}_{s}+\text { cnox } \times N O X_{s}\right) /(1+r)^{s-1}
\end{aligned}
$$

where $\pi$ is the profit, $j$ is index to the generation plant types, $s$ is index to the years, $h$ is index to the hours, $Y_{j, s, h}$ is the power output of the generation plant type $j$ at the hour $h$ in the year $s, o g p$ is the on-grid power price, $f_{j, s}$ is the fuel cost of the generation plant type $j$ in the year $s$ per power generation, $\varepsilon_{j}$ is the consumption of the fuel by the power generation, $v_{j}$ is the variable O\&M cost of the type $j, r$ is the annual discount rate, $X_{j, s}$ is the newly installed capacity of the type $j$ in the year $s, i n v_{j}$ is the investment cost of the type $j$ per installed capacity, $\operatorname{crf} f_{s}$ is the capital recovery factor in the year $s$ per installed capacity, $Q C E R_{s}$ is the quantity of the CER in the year $s$, share is the share rate of the profit, pcer is the CER price, csox is the marginal damage costs of $\mathrm{SO}_{\mathrm{x}}, S O X_{s}$ is the $\mathrm{SO}_{\mathrm{x}}$ emissions in the year $s$, cnox is the marginal damage costs of $\mathrm{NO}_{\mathrm{x}}$, and $N O X_{s}$ is the $\mathrm{NO}_{\mathrm{x}}$ emissions in the year $s$. The equation (1) only includes selling generated power every year as the obtained profits. On the other hand, the equation (2) includes the revenue from the sales of CER and decreased marginal damage costs of air pollutants owing to CDM projects in addition to the equation (1). In this sense, decreased marginal damage costs of air pollutants owing to CDM projects are internalized within the total system cost in the equation (2). 
A variety of constraints are supplied to make the solution more realistic. The constraints include resource availability, installed period and plant life of power generation technologies. The electricity supply must meet instantaneous demand at all times. The demand is given based on annual load demand curve in this study and the balance of the electricity supply and demand is expressed as an equation (3)

$d_{s, h} /\left(1-t d l s_{s}\right)+N_{s, h}=\sum_{j} Y_{j, s, h}$

where $d_{s, h}$ is the demand at the hour $h$ in the year $s, t d l s_{s}$ is the transmission and distribution (T\&D) loss in the year $s$, and $N_{s, h}$ is the input to pumped storage plant at the hour $h$ in the year $s$.

Emissions of certain pollutants by generating electricity are estimated from the model. The emission relation is expressed as an equation (4)

$$
E M_{s, \text { pollut }}=\sum_{j, k} e f_{k, \text { pollut }} \times r d_{j, \text { pollut }} \times F C_{s, j, k}
$$

where pollut represents $\mathrm{CO}_{2}$ emissions and air pollutants; $E M_{s, p o l l u t}$, the emission of pollutant pollut in the year $s$; fuel, the index to fuel types; $e f_{k, p o l l u t}$, the emission factor of pollutant pollut per heat content of fuel $k ; r d_{j, p o l l u t}$, the reduction rate of the emission of 
pollut by type $j$; and $F C_{s, j, k}$, the fuel consumption of fuel $k$ by generation plant of type $j$ in the year $s . F C_{s, j, k}$ is expressed as an equation (5)

$$
F C_{s, j, k}=\sum_{h} Y_{j, s, h} \times g e f_{s, j, k}
$$

where $g e f_{s, j, k}$ represents the consumption of fuel $k$ per kWh by generation plant of type $j$ in the year $s$.

Constraints are added to reflect the characterization of the CDM. Generated amount of CERs has to be equal to the decreased amount of $\mathrm{CO}_{2}$ emissions from the baseline every year and this is indicated in an equation (6)

$$
Q C E R_{s}+E M_{s, C O_{2}, C D M}=E M_{s, C O_{2}, \text { baseline }}
$$

where $E M_{s, C O 2, C D M}$ is the project $\mathrm{CO}_{2}$ emissions in the year $s$ and $E M_{s, C O 2, \text { baseline }}$ is the baseline $\mathrm{CO}_{2}$ emissions in the year $s$. CDM projects will be implemented if they bring financial benefit for the national economy of the host country. The IRR of the project, including the revenues generated from emission credits, is used as an indicator for this criterion (Alexeew et al., 2010). In addition, the benefits from the decrease of $\mathrm{SO}_{\mathrm{x}}$ and $\mathrm{NO}_{\mathrm{x}}$ emissions are included as the co-benefits of developing countries for CDM 
projects. The additionality relation is expressed as equations (7) and (8)

$\sum_{j} \sum_{s} \sum_{h} Y_{j, s, h, C D M} \times\left(\operatorname{ogp} p-f_{j, s} \times \varepsilon_{j}-v_{j}\right) /(1+i r r)^{s-1}-\sum_{j} \sum_{s} X_{j, s, C D M} \times i n v_{j} \times c r f_{s} /(1+i r r)^{s-1}<0$

$\sum_{j} \sum_{s} \sum_{h} Y_{j, s, h, C D M} \times\left(o g p-f_{j, s} \times \varepsilon_{j}-v_{j}\right) /(1+i r r)^{s-1}-\sum_{j} \sum_{s} X_{j, s, C D M} \times i n v_{j} \times c r f_{s} /(1+i r r)^{s-1}$

$+\sum_{s} Q C E R_{s} \times(1-$ share $) \times p c e r /(1+\text { irr })^{s-1}+\sum_{s}\left(\operatorname{csox} \times \operatorname{SOX}_{s}+\right.$ cnox $\left.\times N_{N O X}\right) /(1+\text { irr })^{s-1}>0$

(8)

where irr is the benchmark IRR. The equation (7) shows that the power technologies cannot be introduced by CDM projects without the revenue from the selling CERs and marginal damage costs of $\mathrm{SO}_{\mathrm{x}}$ and $\mathrm{NO}_{\mathrm{x}}$ emissions under provided IRR. On the contrary, the equation (8) indicates that the power technologies exceed the given IRR with with the revenue from the selling CERs and marginal damage costs of $\mathrm{SO}_{\mathrm{x}}$ and $\mathrm{NO}_{\mathrm{x}}$ emissions.

To examine the additionality, the baseline $\mathrm{CO}_{2}$ emission factor is determined by a combination of weighed average of operating margin (OM) emission factor and build margin (BM) emission factor. The $\mathrm{OM}$ is the emission factor that refers to the group of existing power plants whose current electricity generation would be affected by the proposed CDM project activity. The BM is the emission factor that refers to the group of prospective power plants whose construction and future operation would be affected 
by the proposed CDM project activity. The combined margin is expressed as an equation (9)

$E F_{s}=w_{s, O M} \times E F_{s, O M}+w_{s, B M} \times E F_{s, B M}$

where $E F_{s}$ is the baseline emission factor in the year $s, w_{s, O M}$ is the weight of $\mathrm{OM}$ in the year $s, E F_{s, O M}$ is the $\mathrm{OM}$ emission factor in the year $s, w_{s, B M}$ is the weight of BM in the year $s$, and $E F_{S, B M}$ is the BM emission factor in the year $s$.

\section{Data}

\subsection{Generic details}

2031 are taken as the target year in this study. The base year of 2006 is used in line with data availability. Duration of the 25 years is divided into 5 periods of 5 years each. All changes in the actual policies and the installed capacity up to 2010 are included in the model. The discount rate is 9\% (Central Electricity Authority, 2004). We cover two main power grids, NEWNE and Southern grids. Power plants existing and working at the beginning of the base year are decommissioned in accordance with the age 
distribution and the lifetime of these technologies. For example, a power plant which was built in 1990 with thirty years of lifetime is decommissioned in 2020 in the model. No constraint is set on investment money used to meet increased electricity demand in the future. The commercial and T\&D losses have large impacts on electricity generation in India. These amount to $20 \%$ for the base year and the progressive decrease is assumed to reflect an improvement of the transmission loss (Shukla and Dhar, 2009). The commercial and T\&D losses reach $14 \%$ in 2031.

A benchmark IRR of the project should be derived from actual CDM projects and is described in each Project Design Document (PDD). PDD is a precise project description and serves as the basis for the CDM project evaluation and contains baseline study, monitoring plan, stakeholdersôcomments, and details on ecological, socio-economic and development effects. We survey all Indiâิ coal-fired power projects and IRR of $14 \%$ is provided according to the most frequent used IRR among the projects (UNFCCC). Thus, if a project achieves an IRR of more than $14 \%$, it is assumed to have a positive impact on the national economy, whereas a project with an IRR of less than $14 \%$ is ineligible. The share of profit is $2 \%$ as is written in Marrakech Accords. The weights of $\mathrm{OM}$ and $\mathrm{BM}$ are set as 0.5 following the consolidated methodology for grid-connected electricity generation. 
3.2 Specifications of Indiâ̂ power generation technologies

The power generation technologies in this study are determined based on Central Electricity Authority (2004), TERI (2006), and Mallah and Bansal (2010) and shown in Table 1. The data for CCS is derived from IEAGHG (2008) and Black (2010). 
Table 1 Specifications of Indiâ̂ power generation technologies

\begin{tabular}{|c|c|c|c|c|c|c|c|c|}
\hline \multirow[t]{2}{*}{ Technology } & \multirow[t]{2}{*}{$\begin{array}{l}\text { Start } \\
\text { year }\end{array}$} & \multirow[t]{2}{*}{$\begin{array}{l}\text { Lifetime } \\
\text { (years) }\end{array}$} & \multicolumn{2}{|c|}{$\begin{array}{c}\text { Efficiency } \\
(\%)\end{array}$} & \multicolumn{2}{|c|}{ Capacity factor } & \multirow{2}{*}{$\begin{array}{c}\text { Investment } \\
\text { cost } \\
(\mathrm{US} \$ / \mathrm{kW})\end{array}$} & \multirow{2}{*}{$\begin{array}{c}\text { Fixed O\&M } \\
\text { cost } \\
\text { (US\$/kW) }\end{array}$} \\
\hline & & & NEWNE & SOUTH & NEWNE & SOUTH & & \\
\hline CSUB & 2006 & 30 & 30.9 & 34.4 & 0.62 & 0.74 & 1073 & 26.80 \\
\hline $\mathrm{CSC}$ & 2011 & 30 & 37.7 & 37.7 & 0.62 & 0.74 & 1155 & 28.88 \\
\hline CUSC & 2016 & 30 & 44.0 & 44.0 & 0.62 & 0.74 & 1386 & 36.10 \\
\hline Lignite & 2006 & 30 & 26.6 & 26.7 & 0.49 & 0.66 & 1085 & 26.80 \\
\hline NGOC & 2006 & 30 & 28.9 & & 0.57 & & 433 & 6.51 \\
\hline NGCC & 2006 & 30 & $\begin{array}{l}45.2(2006) \\
53.8(2031)\end{array}$ & $\begin{array}{l}43.0(2006) \\
53.8(2031)\end{array}$ & 0.66 & 0.45 & 868 & 8.95 \\
\hline Oil & 2006 & 30 & 51.2 & 42.0 & 0.20 & 0.23 & 315 & 17.90 \\
\hline Nuclear & 2006 & 40 & 31.7 & 31.7 & 0.9 & 0.9 & 1627 & 40.68 \\
\hline $\begin{array}{l}\text { Small } \\
\text { hydro }\end{array}$ & 2006 & 50 & & & 0.32 & 0.38 & 2441 & 36.61 \\
\hline $\begin{array}{l}\text { Large } \\
\text { hydro }\end{array}$ & 2006 & 50 & & & 0.35 & 0.44 & 1085 & 16.27 \\
\hline Wind & 2006 & 30 & & & $0.2 / 0.3$ & $0.2 / 0.3$ & 1031 & 15.46 \\
\hline Pump & 2006 & 50 & & & 0.16 & 0.23 & 759 & 16.27 \\
\hline $\begin{array}{l}\text { USC with } \\
\text { CCS }\end{array}$ & 2021 & 30 & 36.6 & 36.6 & 0.62 & 0.74 & 2557 & 62.37 \\
\hline $\begin{array}{l}\text { IGCC with } \\
\text { CCS }\end{array}$ & 2021 & 30 & 40.3 & 40.3 & 0.62 & 0.74 & 2174 & 48.44 \\
\hline $\begin{array}{l}\text { NGCC with } \\
\text { CCS }\end{array}$ & 2021 & 30 & $\begin{array}{l}42.2(2021) \\
45.6(2031)\end{array}$ & $\begin{array}{l}42.2(2021) \\
45.6(2031)\end{array}$ & 0.66 & 0.45 & 1876 & 26.46 \\
\hline
\end{tabular}

All the cost data is shown in constant 2006US\$. The efficiencies and the capacity factor of the existing plants are calculated from actual data for the two grids. Advanced thermal plants and renewable energy are included as power generation technologies in addition to existing technologies. For coal-fired power generation, existing plants are based on sub-critical steam pressure systems (CSUB) whose thermal efficiencies are 
$30.9 \%$ in the NEWNE grid and 34.4\% in the Southern grid in 2006 and lignite-fired power generation (LIG). Coal supercritical (CSC) and coal ultra supercritical (CUSC) are introduced from 2011 and 2016 respectively. The efficiency of NGCC provided by TERI (2006) is higher than the existing efficiency of NGCC. Instead of assuming advanced type of NGCC, the efficiency of NGCC is gradually improved and reaches $53.8 \%$ provided by TERI (2006) in 2031. The variable O\&M costs are estimated from US\$/kW and capacity factor.

Three technologies are considered for CCS projects in the CDM, USC with CCS, IGCC with CCS, and NGCC with CCS in this study. The data for CCS is derived from IEAGHG (2008) which develops cost flow sheets for key CCS components for global and Indian conditions. The costs include capture costs, transport costs by pipeline or shipping, and storage costs by $\mathrm{CO}_{2}$ injections. Since the detailed capture costs are provided and the capture costs account for $60-80 \%$ of the CCS system costs (IEAGHG, 2008), the sum of the transport costs and storage costs are assumed to be $30 \%$ of total costs. Water gas shift reactors are applied as the way of the removal of $\mathrm{CO}_{2}$ for IGCC with CCS. Amine-based capture is applied for USC with CCS and NGCC with CCS. The generating efficiency of IGCC is $44.0 \%$ in 2006 (TERI 2006). A gradual improvement to $48.0 \%$ is assumed from the technological roadmap of Japan. The efficiency falls from $48.0 \%$ to $40.3 \%$ with CCS. The capture system is assumed to have 
a $90 \%$ of capture efficiency. The removal rate of $\mathrm{SO}_{\mathrm{x}}$ and $\mathrm{NO}_{\mathrm{x}}$ in capture process is assumed as $100 \%$ and $2 \%$ respectively (Iijima et al., 2007; Koornneef et al., 2012). The levelized costs of electricity (LCOE) of 2006 by plant type in each grid are calculated with $9 \%$ of discount rate and are shown in Table 2.

Table 2 LCOE by plant type in each grid (USD/kWh)

\begin{tabular}{lrrlrr}
\hline \multicolumn{1}{l}{ NEWNE } & \multicolumn{2}{l}{ SOUTH } & \multicolumn{1}{c}{ NEWNE } & \multicolumn{1}{c}{ SOUTH } \\
\hline CSUB & 0.021 & 0.018 & Nuclear & 0.009 & 0.008 \\
CSC & 0.020 & 0.018 & Small hydro & 0.019 & 0.016 \\
CUSC & 0.020 & 0.018 & Large hydro & 0.007 & 0.006 \\
Lignite & 0.026 & 0.023 & WIND20/30 & $0.020 / 0.014$ & $0.020 / 0.014$ \\
NGOC & 0.025 & 0 & PUMP & 0.011 & 0.008 \\
NGCC & 0.017 & 0.017 & USC with CCS & 0.031 & 0.027 \\
OIL & 0.069 & 0.076 & IGCC with CCS & 0.027 & 0.024 \\
& & & NGCC with CCS & 0.028 & 0.052 \\
\hline
\end{tabular}

The differences among grids reflect the differences of the capacity factor. The levelized costs of CCS are higher except for oil-fired power generation. $\mathrm{CCS}$ requires $\mathrm{CO}_{2}$ prices to be installed.

In addition, $\mathrm{DeSO}_{\mathrm{x}}$ and $\mathrm{DeNO}_{\mathrm{x}}$ technologies are equipped to fossil-fired power generation for the purpose of the mitigation of $\mathrm{SO}_{\mathrm{x}}$ and $\mathrm{NO}_{\mathrm{x}}$ emissions. Rather than limiting their quantity, the height of the flue gas stack is regulated under current policy. Currently, only two power plants in India have installed a flue gas desulfurization (FGD) as the power plants are close to the densely populated city and an ecologically 
sensible area (Chikkatur and Sagar, 2007). Also, deployment of $\mathrm{DeNO}_{\mathrm{x}}$ technology has been held by lack of statutory standards for $\mathrm{NO}_{\mathrm{x}}$ emissions (Chikkatur and Sagar, 2007). As a result, the compounded annual growth rate of $\mathrm{SO}_{\mathrm{x}}$ and $\mathrm{NO}_{\mathrm{x}}$ emissions is $6.8 \%$ and 7.3\% between 1985 and 2005 in Indiâ̂ power sector (Garg et al., 2006).

The assumption of the FGD is based on ESMAP (2004a) and ESMAP (2004b) and the assumption related to the LNB and the SCR is determined by taking the technological level of the FGD into account and their specifications are shown in Table 3.

Table 3 Specifications of $\mathrm{DeSO}_{\mathrm{x}}$ and $\mathrm{DeNO}_{\mathrm{x}}$ technologies

\begin{tabular}{lrrrr}
\hline & $\begin{array}{c}\text { Investment cost } \\
(\mathrm{USD} / \mathrm{kW})\end{array}$ & $\begin{array}{c}\text { Variable O\&M cost } \\
(\mathrm{USD} / \mathrm{kWh})\end{array}$ & $\begin{array}{c}\text { Efficiency loss } \\
(\%)\end{array}$ & \multicolumn{2}{c}{$\begin{array}{c}\text { Removal rate } \\
(\%)\end{array}$} \\
\hline FGD & 63.5 & 0.00338 & 5 & 80 \\
LNB & 7.61 & 0 & 0 & $30 / 40$ \\
SCR & 63.5 & 0.00021 & 0.5 & $77 / 80$ \\
\hline
\end{tabular}

The left side of the removal rate of the LNB and the SCR corresponds to coal- and oil-fired power generations and the right side corresponds to gas-fired power generations. These technologies are installed on both the existing plants and the newly installed plants.

\subsection{Fuel}


Future power mix is greatly dependent on fuel prices. The domestic fuel prices in the base year of 2006 are derived from TERI (2006). The escalations of the fuel prices are assumed to change in collaboration with the international prices of fossil fuels and are derived from IEA (2010). The energy prices in the time horizon are shown in Table 4.

Table 4 Fuel prices

\begin{tabular}{llrrrrrr}
\hline & Unit & 2006 & 2011 & 2016 & 2021 & 2026 & 2031 \\
\hline Coal & $\mathrm{t}$ & 33.0 & 51.2 & 52.2 & 56.0 & 57.9 & 59.4 \\
Lignite & $\mathrm{t}$ & 25.8 & 40.0 & 40.8 & 43.8 & 45.2 & 46.4 \\
Gas & $10^{3} \mathrm{~m}^{3}$ & 0.13 & 0.18 & 0.21 & 0.24 & 0.26 & 0.28 \\
Oil & $\mathrm{t}$ & 668.6 & 866.3 & 1175.9 & 1355.0 & 1476.0 & 1584.9 \\
\hline
\end{tabular}

The prices rise steadily in response to expected higher demand and lower resource availability in the world. Thus, the oil and the gas prices rise relatively faster than the coal prices.

To calculate $\mathrm{CO}_{2}$ emitted through the combustion of fossil fuels, $\mathrm{CO}_{2}$ emissions intensity of fossil fuel is represented. The intensity is obtained from Hondo et al. (1998) and shown in Table 5. 


\subsection{Energy resources}

Nuclear power generation and renewable energy play important roles in decreasing $\mathrm{CO}_{2}$ emissions and air pollutants. However, these technologies have social and resource constraints. Upper bound of the capacity installations are given to reflect the constraints. The upper bound of nuclear power generation is applied based on national electricity plan (Central Electricity Authority, 2004). The resource constraint of renewable energy corresponds with the technological potential for wind and hydroelectric power. The potential of hydroelectric power and wind power is derived from Ramanathan and Abeygunawardena (2007) and Ministry of New and Renewable Energy respectively.

Given its fuel-efficiency, low environmental burdens, and cost-competitiveness, gas demand is expected to increase in the future. However, domestic supply is not enough to assure the future gas requirements in India. Natural gas may be imported in the form of LNG by trans-national pipelines. India imports LNG by two terminals and new three terminals are being planned. The power sector consumes about $40 \%$ of the gas and has been the core consumers of natural gas since 2001 (Infraline Energy Research and 
Information Services, 2006). This share is expected to pursuit in the future (Gupta, 2002). The daily availability of natural gas in India through domestic extraction and import through LNG terminals and pipelines are derived from TERI (2006).

\subsection{Electricity demand}

Electricity demand is the principal driver of electricity generation from the power sector. Electrical demand has been growing in India and is expected to rise significantly in the future. The demand growth is a result of strong economic growth and greater accessibility to electricity grids during the period. This increase is expected to persist in medium and long terms. The future electricity demand is determined based on the projection of IEEJ (2009). The projection is based on an econometric model which considers social and economical changes to examine future Asian energy demand. The model also contains a shift of end-use technologies. The annual electricity growth rates are $5.8 \%$ from 2007 to 2020, 5.7\% from 2020 to 2030, and 5.5\% from 2030 to 2035 .

The annual load duration curves of the two power grids are developed. State-wise peak met demand is derived from CEA (2008). Annual load duration curves of Southern grid is obtained from Southern regional power committee (2007) and those of NEWNE is estimated based on the annual load duration curves of Southern grid. The growth rates 
are assumed to be identical among each grid and each hour.

\subsection{Environmental regulation}

Government of India has formally conveyed to the UNFCCC that India will endeavour to reduce the emissions intensity of its GDP by $20-25 \%$ by 2020 in comparison with the 2005 level through domestic mitigation actions. This reduction target involves the power sector. This decrease trend is expected to continue in the future. The cap is applied in this study and shown in Table 6 .

Table 6 Cap of $\mathrm{CO}_{2}$ emissions $\left(\mathrm{gCO}_{2} / \mathrm{kWh}\right)$

\begin{tabular}{rrrrrr}
\hline 2006 & 2011 & 2016 & 2021 & 2026 & 2031 \\
\hline 805.34 & 738.23 & 671.12 & 604.01 & 604.01 & 604.01 \\
\hline
\end{tabular}

\subsection{Design of scenarios}

The baseline scenario is estimated without an inclusion of CDM projects and marginal damage costs of air pollutants. The scenario is developed to provide the baseline of CDM projects.

Environment damage costs from GHG emissions and air pollutants are estimated 
with different value method. $\mathrm{CO}_{2}$ emission reduction benefits vary widely due to a complexity of climate change impacts. $\mathrm{CO}_{2}$ price is determined in the emission market and there is a large uncertainty in the future. Fuel combustion causes the adverse effects of exposure to ambient air pollution such as increased respiratory illness and premature deaths. Increased use of fossil fuels linking to emission of air pollutants contributes to environmental damage costs. Marginal damage costs of $\mathrm{SO}_{\mathrm{x}}$ and $\mathrm{NO}_{\mathrm{x}}$ emissions are estimated by value of life year lost which basically assigns a willingness-to-pay to the risk of reducing life expectancy. Even though they still inherit uncertainty, marginal damage costs are determined and will not change largely in the future.

Three additional scenarios are developed to examine the effects on the installed capacity of IGCC with CCS projects in the CDM under the different marginal damage costs of the air pollutants in this study, a CDM_NC (No Cost) scenario, a CDM_LC (Low Cost) scenario, and a CDM_HC (High Cost) scenario. The CDM_NC scenario is developed with no marginal damage costs of the air pollutants. In fact, the CDM_NC scenario models the potential of the installed capacity of IGCC with CCS under the current CDM regime. There are few studies related to marginal damage costs of the air pollutants in India due to limited available data, while a number of their estimations are found in developed countries (for example Krewitt, 2002). We use the marginal $\mathrm{SO}_{\mathrm{x}}$ and $\mathrm{NO}_{\mathrm{x}}$ damage costs of Mumbai applying a rapid damage assessment model (Lvovsky et 
al., 2000). The model uses a simple dispersion model to estimate source-specific emissions to effects on ambient conditions and exposure levels with fuel use inventory and emission inventory. From the exposure levels, health impacts are assessed using dose-response functions that link variations in the ambient levels of certain pollutants to health effects. The study uses a coherent set of estimates based on the willingness-to-pay approach to monetize the health impacts. The marginal damage costs of power plants are estimated at US\$51/t for $\mathrm{SO}_{\mathrm{x}}$ and US\$20/t for $\mathrm{NO}_{\mathrm{x}}$ and the marginal damage costs averaged across fuel uses are estimated at US\$549/t for $\mathrm{SO}_{\mathrm{x}}$ and US\$450/t for $\mathrm{NO}_{\mathrm{x}}$ in the study. These vary due to the fact that fuel users include small sources of air pollution, vehicles, household stoves, and small industries and business which are closer to peoplê̂ living area than power plants. The marginal damage costs of US\$51/t for $\mathrm{SO}_{\mathrm{x}}$ and US\$20/t for $\mathrm{NO}_{\mathrm{x}}$ are added to IGCC with CCS projects in the CDM in the CDM_LC scenario. In the CDM_HC scenario, the marginal damage costs of US $\$ 549 / \mathrm{t}$ for $\mathrm{SO}_{\mathrm{x}}$ and US $\$ 450 / \mathrm{t}$ for $\mathrm{NO}_{\mathrm{x}}$ are applied to IGCC with CCS projects in the CDM.

Kapila (2009) states that heavy industry sector which significantly uses electricity is expected to expand its production by 4 to 5 folds by 2020 with ñरeavy carbon footprintsò with a strong economic growth and CCS introduction seems very timely. Thus, the year when CDM projects are implemented is set as 2021 in accordance with the suitable timing of the CCS introduction. The estimated installed capacity and power 
generation until 2016 is fixed from the baseline in the three scenarios. In addition, the installed capacity and the power generation of must-run technologies are fixed from the baseline through the time horizon. The length of the crediting period is 10 years according to the PDDs submitted as India@̂ coal-fired power projects.

\section{Results}

This study evaluates impacts of including the co-benefits into the CDM on potential of installed capacity of CCS projects with an LP model. In addition, cumulative emissions of $\mathrm{CO}_{2}$ and air pollutants; and reduction benefits yielded from CCS projects are estimated under different CER prices. The relationship between CER prices and marginal damage costs of air pollutants is identified.

4.1 Installed capacity in the baseline scenario

Fig. 1 shows installed capacity in the baseline scenario. 


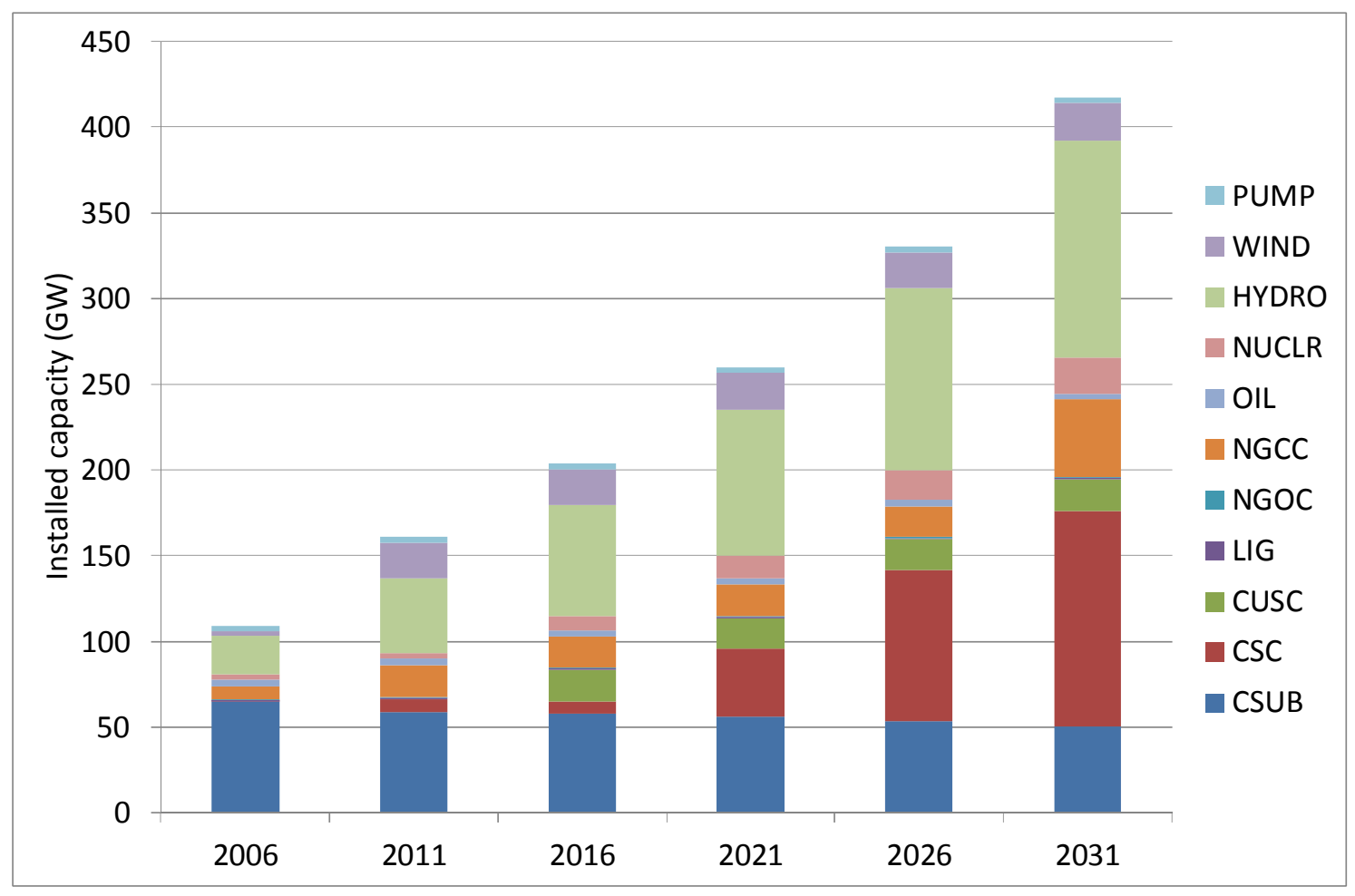

(NEWNE)

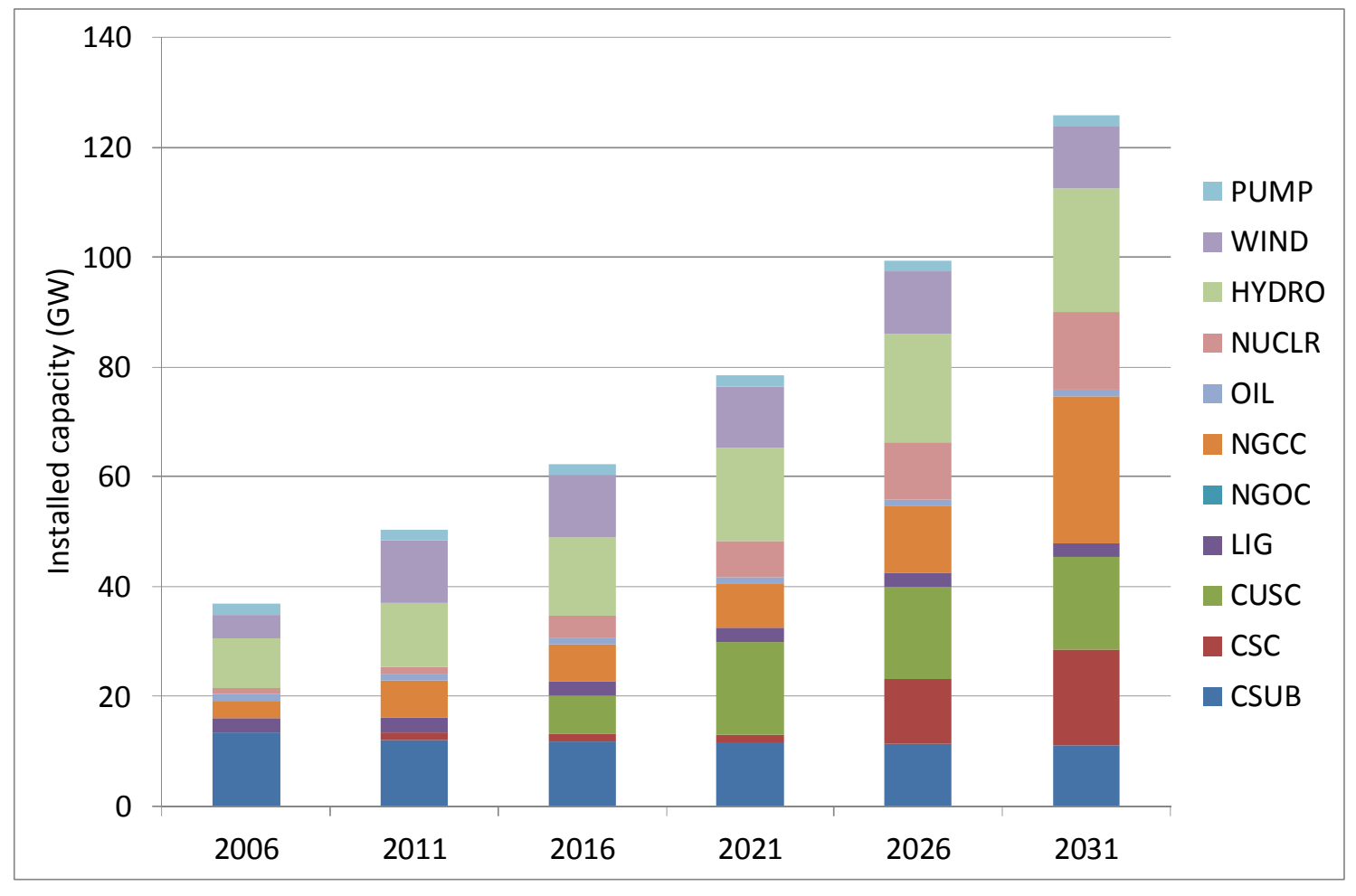

(South)

Fig.1 Installed capacity in the baseline

Total installed capacity increases from $109.05 \mathrm{GW}$ to $417.01 \mathrm{GW}$ in the NEWNE grid 
and from $36.96 \mathrm{GW}$ to $125.76 \mathrm{GW}$ in the Southern grid. Coal-fired generation has been dominant through the objective term and accounts for $46.80 \%$ in the NEWNE grid and $38.06 \%$ in the Southern grid of total installed capacity in 2031. CSC increases in the NEWNE grid and CUSC increases in Southern grids in 2021, thus they are substituted by CDM projects in this study. First, NGCC increases with low investment costs. However, with the increase of natural gas, installed capacity of NGCC hardly increase up to 2021. With the improvement of the efficiency of NGCC, installed capacity increases after 2026. Large hydro and nuclear are installed up to the upper bound due to low fuel cost. Wind in the Southern grid does not reach the upper bound due to the low availability.

4.2 Installed capacity by CDM projects

Fig.2 shows installed capacity of IGCC with CCS projects in the CDM under different CER prices up to $\mathrm{US} \$ 60 / \mathrm{tCO}_{2}$. 

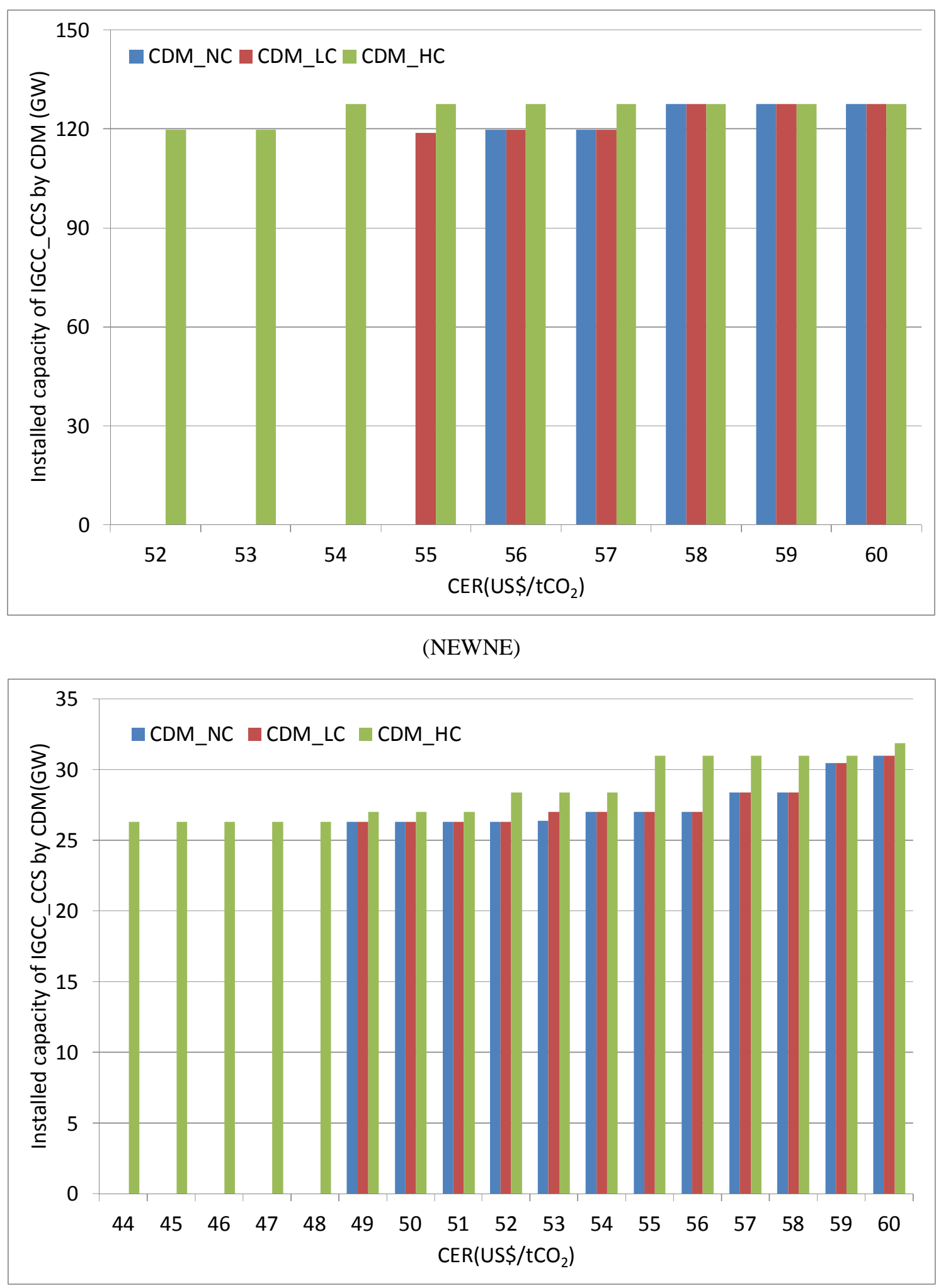

(South)

Fig.2 Installed capacity of IGCC with CCS by CDM projects 
Only IGCC with CCS is installed in this model since adding CCS to PC and NGCC provides more costly than IGCC. In particular, NGCC with CCS is not installed since coal price is relatively cheaper than gas in the case of India. Since USC with CCS and NGCC with CCS are not introduced, the results in regard with these technologies are omitted.

No power plants are installed in the CDM when the CER prices are below US $\$ 56 / \mathrm{tCO}_{2}$ in the NEWNE grid and $\mathrm{US} \$ 49 / \mathrm{tCO}_{2}$ in the Southern grid in the CDM_NC scenario. India obtains no profit through selling the CERs generated by IGCC with CCS projects in the CDM below US $\$ 49 / \mathrm{tCO}_{2}$. The CER prices of US $\$ 49 / \mathrm{tCO} \mathrm{CO}_{2}$ make IGCC with CCS projects in the CDM economically viable with $26.3 \mathrm{GW}$ in the South grid. In the NEWNE grid, IGCC with CCS is installed at $119.45 \mathrm{GW}$ at the CER price of US $\$ 56 / \mathrm{tCO}_{2}$. This difference is attributed to the difference of power generation of 2021 in the baseline scenario and the capacity factor of IGCC with CCS in each grid. At the CER price of US $\$ 60 / \mathrm{tCO}_{2}$, IGCC with CCS is installed at $127.68 \mathrm{GW}$ in the NEWNE grid and $30.95 \mathrm{GW}$ in the Southern grid. Thus, IGCC with CCS is substantially installed in the CDM when it becomes economically viable with a substantial decrease of $\mathrm{CO}_{2}$ emissions. This is due to the fact that CCS reduces $\mathrm{CO}_{2}$ emissions drastically at once.

When co-benefits are included, IGCC with CCS becomes economically viable at a lower CER price. IGCC with CCS is installed at the CER price of US $\$ 55 / \mathrm{tCO}_{2}$ in the 
NEWNE grid in the CDM_LC scenario while IGCC with CCS is installed at the same price in the Southern grid. In the CDM_HC scenario, IGCC with CCS is installed at the CER price of US\$52/tCO 2 in the NEWNE grid and US\$44/tCO $\mathrm{H}_{2}$ in the Southern grid. Thus, CCS projects in the CDM will be more widespread at lower CER prices with an inclusion of co-benefits.

4.3 Cumulative emissions from 2021 and 2031

Fig. 3 and Fig. 4 show cumulative $\mathrm{CO}_{2}$ emissions and air pollutants from 2021 to 2031 under different CER prices. 


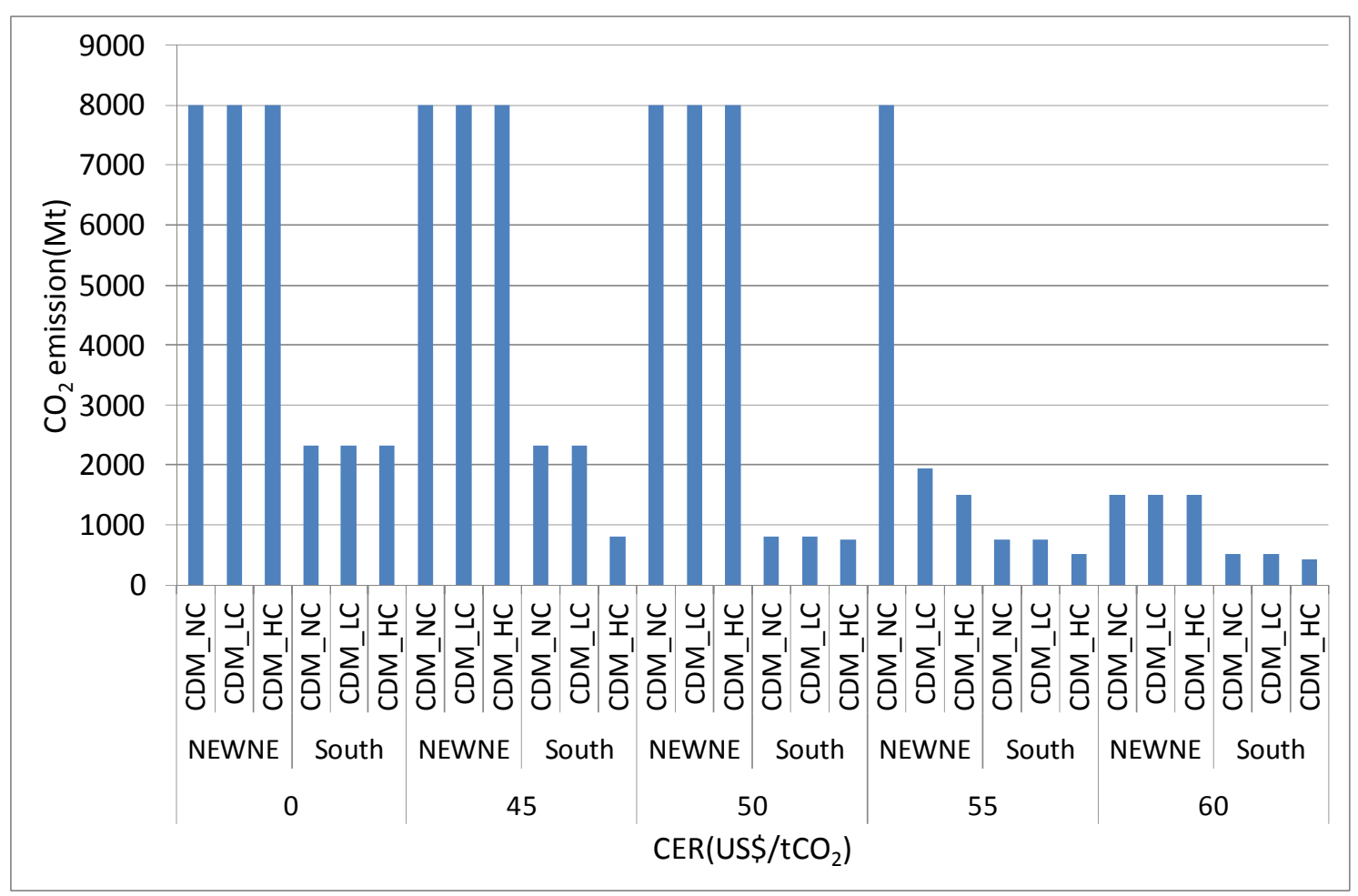

Fig.3 Cumulative $\mathrm{CO}_{2}$ emissions from 2021 to 2031 under three scenarios

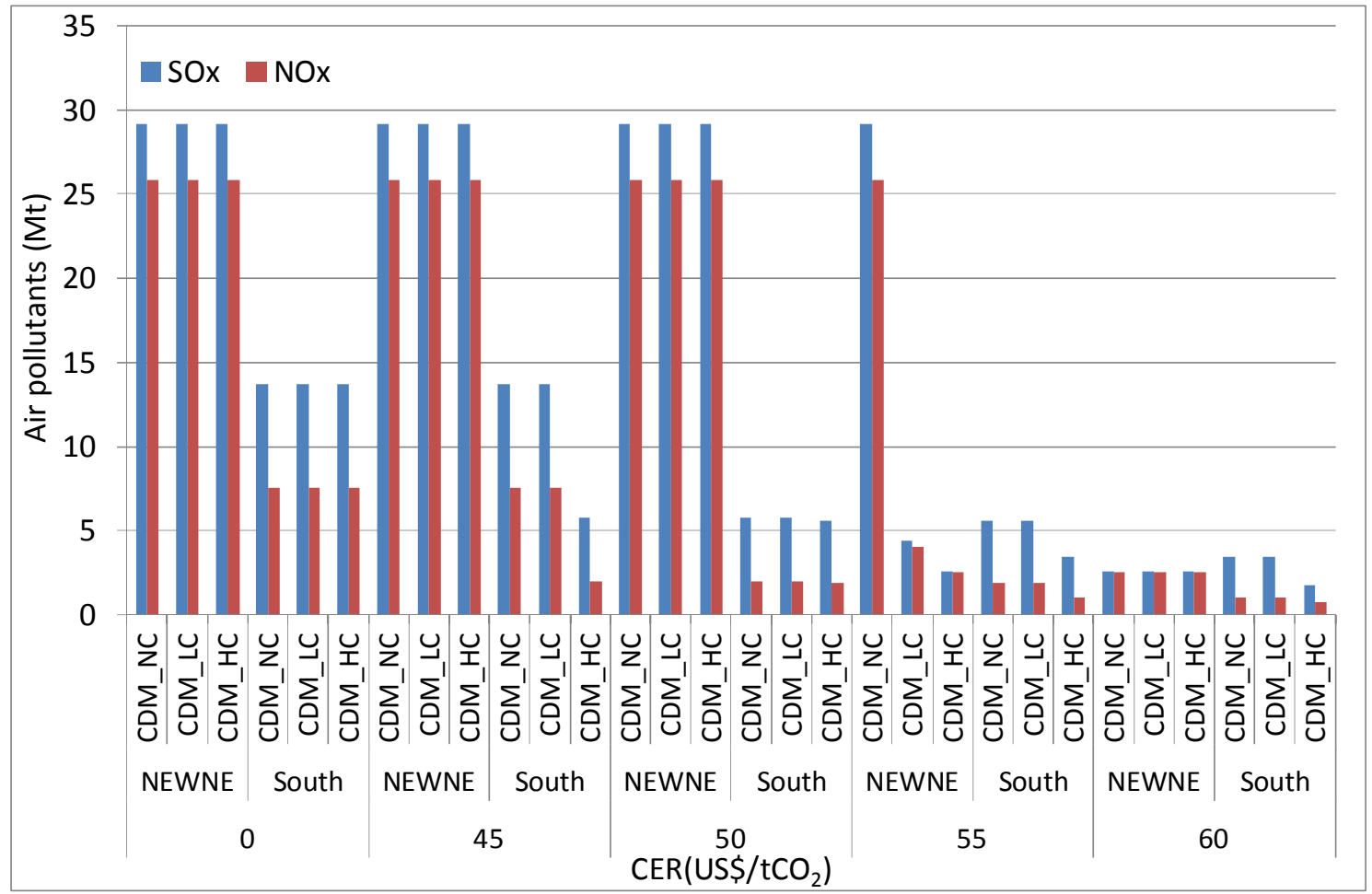

Fig.4 Cumulative air pollutants from 2021 to 2031 under three scenarios

Without CDM projects, the cumulative $\mathrm{CO}_{2}$ emissions are $8013.39 \mathrm{tCO}_{2}$ in the $\mathrm{NEWNE}$ 
grid and 2324.36 $\mathrm{tCO}_{2}$ in the Southern grid. The cumulative $\mathrm{SO}_{\mathrm{x}}$ and $\mathrm{NO}_{\mathrm{x}}$ emissions are 29.15tSO $\mathrm{SA}_{\mathrm{x}}$ and $25.86 \mathrm{tNO} \mathrm{x}_{\mathrm{x}}$ in the NEWNE grid; $13.73 \mathrm{tSO}_{\mathrm{x}}$ and $7.53 \mathrm{tNO}_{\mathrm{x}}$ in the Southern grid. At the CER price of US\$60/tCO in the NEWNE grid and $77.89 \%$ in the Southern grid from the baseline. The cumulative $\mathrm{SO}_{\mathrm{x}}$ and $\mathrm{NO}_{\mathrm{x}}$ emissions decrease $91.11 \%$ and $90.21 \%$ in the NEWNE grid; $74.57 \%$ and $86.77 \%$ in the Southern grid from the baseline. This is owing to the introduction of IGCC with CCS by CDM.

The emissions decrease in accordance with the increase of the marginal damage costs of $\mathrm{SO}_{\mathrm{x}}$ and $\mathrm{NO}_{\mathrm{x}}$ owing to IGCC with CCS installed by the CDM projects at lower CER prices. In the CDM_LC scenario, the inclusion of the co-benefits affects on the emissions at the CER price of $\mathrm{US} \$ 55 / \mathrm{tCO}_{2}$ in the NEWNE grid. In the CDM_HC scenario, the inclusion of the co-benefits affects on the emissions at the CER prices of $\mathrm{US} \$ 55 / \mathrm{tCO}_{2}$ in the NEWNE grid and US\$45/tCO 2 in the Southern grid. However, the difference is small among the scenarios at different CER prices. This is due to the fact that IGCC with CCS is installed at once and reaches nearly potential when it becomes economically viable. 
4.4 Emission reduction benefits from $\mathrm{CDM}$ projects

Fig. 5 shows the cumulative emission reduction benefits from 2021 to 2031.

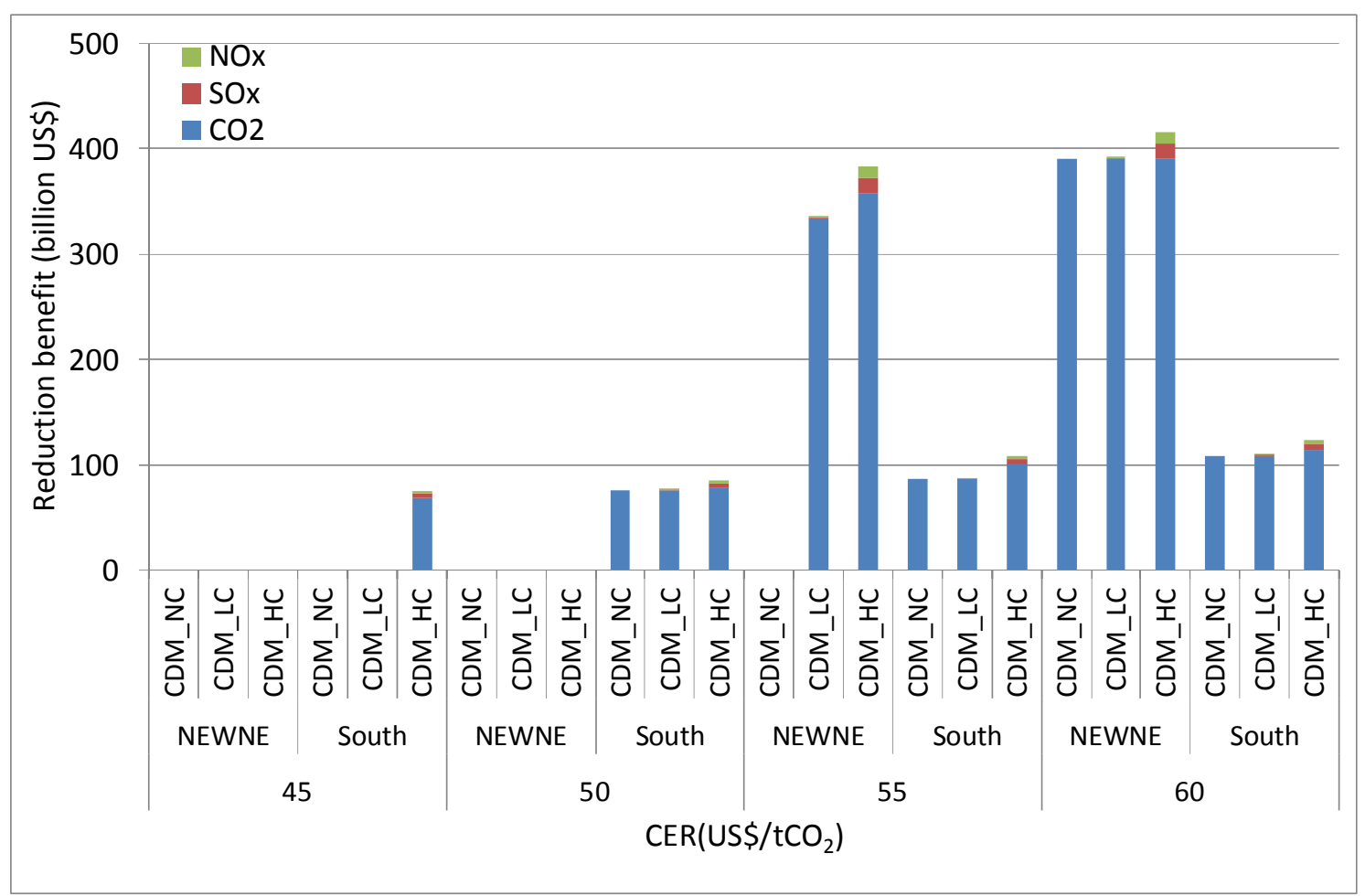

Fig.5 Reduction benefit from 2021 to 2031 under three scenarios

Although reduction rates of air pollutants from the baseline are higher than those of $\mathrm{CO}_{2}$ emissions, reduction benefits from air pollutants are limited. This is due to the fact that emitted amount of $\mathrm{CO}_{2}$ is much larger than that of air pollutants in the baseline. Thus, reduction amount of $\mathrm{CO}_{2}$ emissions from the baseline is much larger than that of air pollutants. The reduction benefits of air pollutants account for $0.6 \%$ of total reduction 
benefits in the CDM_LC scenario. In the CDM_HC scenario, the reduction benefits of air pollutants account for between $6.03 \%$ and $9.11 \%$ of total reduction benefits.

\subsection{Sensitivity analysis}

In order to clarify the relationship between CER prices and marginal damage costs of air pollutants, sensitivity analysis is conducted. The marginal damage costs of $\mathrm{SO}_{\mathrm{x}}$ and $\mathrm{NO}_{\mathrm{x}}$ are divided equally among eight between the marginal damage costs of the CDM_LC scenario and the CDM_HC scenario. Fig.6 shows the lowest CER prices of IGCC with CCS installed by the CDM under different marginal damage costs of $\mathrm{SO}_{\mathrm{x}}$ and $\mathrm{NO}_{\mathrm{x}}$. 


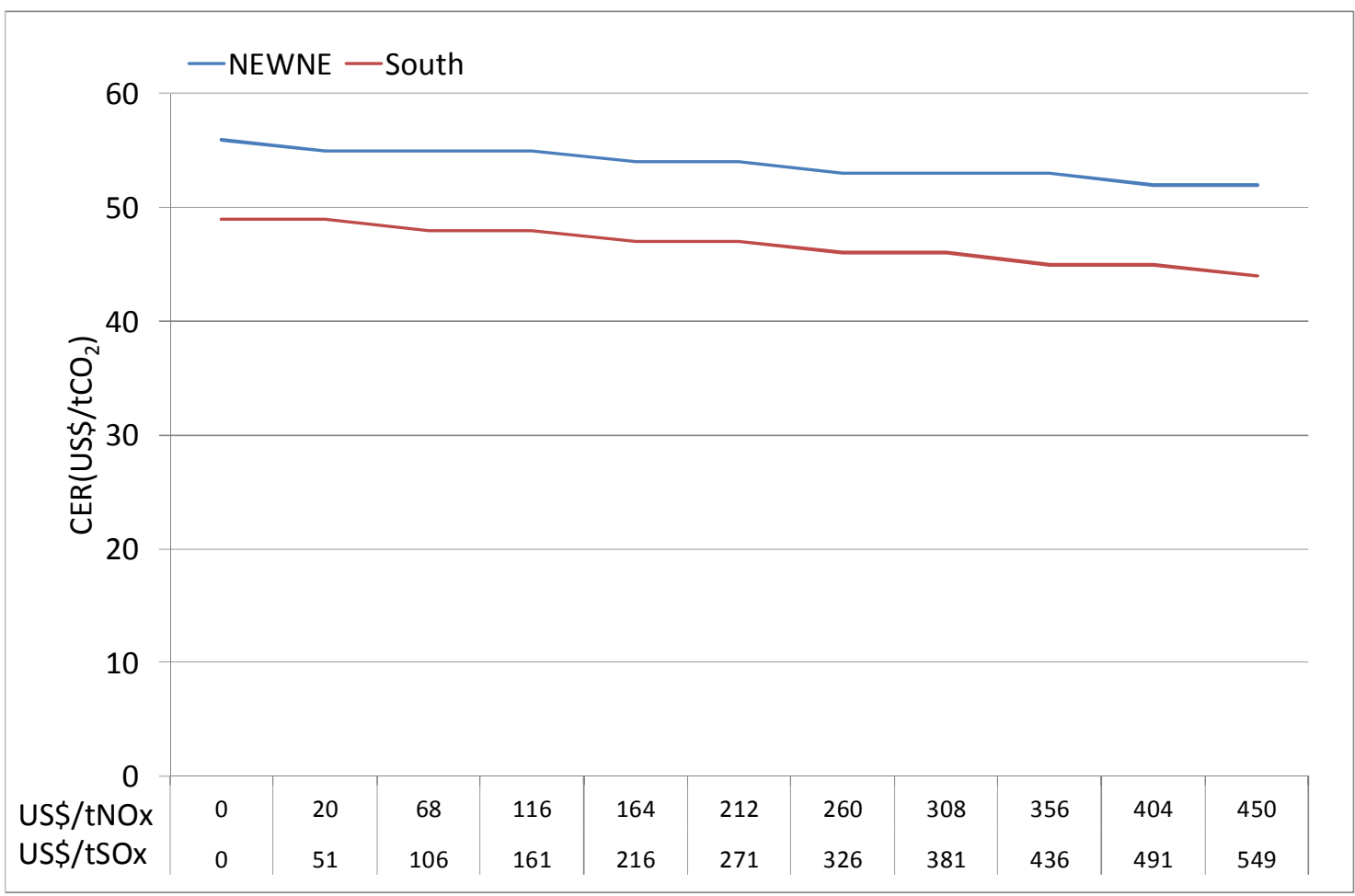

Fig.6 The lowest CER prices of IGCC with CCS installed by the CDM under different marginal damage costs of $\mathrm{SO}_{x}$ and $\mathrm{NO}_{\mathrm{x}}$

CER prices decrease by $\mathrm{US} \$ 1 / \mathrm{tCO}_{2}$ as $\mathrm{US} \$ 200 / \mathrm{t}$ increase in the sum of marginal damage costs of $\mathrm{SO}_{\mathrm{x}}$ and $\mathrm{NO}_{\mathrm{x}}$ in the Southern grid. On the other hand, about US\$250/t increase in the sum of marginal damage costs of $\mathrm{SO}_{\mathrm{x}}$ and $\mathrm{NO}_{\mathrm{x}}$ corresponds with US $\$ 1 / \mathrm{tCO}_{2}$ in the NEWNE grid. Since coal-fired plants relative to gas-fired plants generate in the Southern grid in the baseline more than the NEWNE grid, the $\mathrm{SO}_{\mathrm{x}}$ and $\mathrm{NO}_{\mathrm{x}}$ emission factors relative to $\mathrm{CO}_{2}$ emission factors are higher in the NEWNE grid. Thus, the impacts of the co-benefits are larger in the Southern grid. This is found that including the co-benefits into CDM attracts the grids where coal-fired power generates more largely than gas-fired power. However, it can be concluded that the affects of the 
co-benefits are limited in the case of CCS.

\section{Conclusion}

CCS is one of the most effective ways to combat global warming in medium and long terms. CCS is discussed to be included as project activities under the CDM. Coal-fired power generation with CCS potentially contributes to achieve the decrease of $\mathrm{CO}_{2}$ emissions and air pollutants as well. An LP model is developed to evaluate the potential of installed capacity of IGCC with CCS in the CDM in Indiâ̂ power sector. The affects of inclusion of co-benefits on the potential of installed capacity of IGCC with CCS are examined at different CER prices with a scenario analysis. Three results are obtained from this study.

First, large quantity of IGCC with CCS becomes realizable when the CER prices are above US\$56/tCO $\mathrm{tn}_{2}$ in the NEWNE grid and above US\$49/tCO $\mathrm{C}_{2}$ in the Southern grid. USC with CCS and NGCC with CCS are not installed since IGCC with CCS is installed significantly as the CER prices increase. From the model calculation, it is found that IGCC with CCS is more competitive than USC with CCS and NGCC with CCS owing to a relatively low LCOE in the case of India. A limited number of IGCC with CCS increases up to $\mathrm{US} \$ 60 / \mathrm{CO}_{2}$. CCS has a threshold for the introduction by CDM projects 
since CCS reduces $\mathrm{CO}_{2}$ emissions dramatically once. Thus, most of the CCS potential in the CDM can be realized when IGCC with CCS becomes economically viable.

Second, this is found that including co-benefits contributes to decrease $\mathrm{CO}_{2}$ emissions and air pollutants with introduction of IGCC with CCS in the CDM at lower CER prices than the case of the absence of co-benefits. IGCC with CCS is installed at lower CER prices when the marginal damage costs of $\mathrm{SO}_{\mathrm{x}}$ and $\mathrm{NO}_{\mathrm{x}}$ are added to the CER price. Thus, $\mathrm{CO}_{2}$ emissions and air pollutants decrease from the baseline at lower CER prices.

Third, the effects of the co-benefits are limited in the case of CCS because CCS contributes to reduce larger amount of $\mathrm{CO}_{2}$ emissions than that of air pollutants. It is clarified from the sensitivity analysis that total air pollutants of US $\$ 200 / \mathrm{t}$ in the Southern grid and US\$250/ $t$ in the NEWNE grid lead to CER prices of US $\$ 1 / \mathrm{tCO}_{2}$ reduction. Thus, addressing the co-benefits attracts developing countries where marginal damage costs of air pollutants are high to include CCS projects in the CDM.

\section{Acknowledgement}

This research was supported by the Environment Research and Technology Development Fund (E-1001) of the Ministry of the Environment, Japan. 


\section{References}

Alexeew, J., Bergset, L., Meyer, K., Petersen, J., Schneider, L., Unger, C., 2010. An analysis of the relationship between the additionality of CDM projects and their contribution to sustainable development. International Environmental Agreements: Politics, Law and Economics, 10, 233-248.

Bakker, S., Coninck, H.D., Groenenberg, H., 2010. Progress on including CCS projects in the CDM: Insight on increased awareness, market potential and baseline methodologies. International Journal of Greenhouse Gas Control, 4, 321-326.

Black, J.B., 2010. Cost and performance baseline for fossil energy plants, Bituminous coal and natural gas to electricity, Volume 1, DOE/NETL-2010/1397.

Central Electricity Authority, 2004. National Electricity Plan (Volume -I), Central Electricity Authority, New Delhi.

Central Electricity Authority, 2008. All India Electricity Statistics and General Review 2008, Central Electricity Authority, New Delhi.

Chen, Q., Kang, C., Xia, Q., Guan, D., 2011. Preliminary exploration on low-carbon technology roadmap of Chinâ̂ power sector.. Energy, 36, 1500-1512.

Chikkatur, A.P., Sagar, A.D., 2007. Cleaner power in India: towards a clean-coal-technology roadmap, BCSIA Discussion Paper Series, Belfer Center for Science and International Affairs, Harvard University. 
Condor, J., Unatrakarn, D., Asghari, K., Wilson, M., 2011. Current status of CCS initiatives in the major emerging economies. Energy Procedia, 4, 6125-6132.

EEA, 2011. Air pollution impacts from carbon capture and storage (CCS). European Environment Agency (EEA) Technical report, 14.

ESMAP, 2004a. Environmental issues in the power sector: long-term impacts and policy options for Karnataka, Energy Sector Management Assistance Program, World Bank.

ESMAP, 2004b. Environmental issues in the power sector: long-term impacts and policy options for Rajasthan, Energy Sector Management Assistance Program, World Bank.

Garg, A., Shukla, P.R., Kapshe, M., 2006. The sectoral trends of multigas emissions inventory of India. Atmospheric Environment, 40, 4608-4620.

Ghosh, S., 2010. Status of thermal power generation in India - Perspectives on capacity, generation and carbon dioxide emissions. Energy Policy, 38, 6886-6899.

Gupta, S.P., 2002. Indian Vision 2020, Planning Commissions Report, Government of India.

Hondo, H., Tonooka, Y. and Uchiyama Y., 1998. Environmental burdens associated production in Japan using input-output table, Socio-economic Research Center, Reo. Y97017.

IEA, 2008. World Energy Outlook 2008, International Energy Agency.

IEA, 2010. World Energy Outlook 2010, International Energy Agency.

IEAGHG, 2008. A regional assessment of the potential for CO2 storage in the Indian subcontinent, IEA Greenhouse Gas R\&D Programme. 
IEEJ, 2009. Asia/world energy outlook 2009 ï The role of technology towards the resolution of energy \& environmental issues in Asia ï . Japan, The Institute of Energy Economics.

Iijima, M., Takashina, T., Iwasaki, S., Kishimoto, S., 2007. Long-term demonstration of CO2 recovery from the flue gas of a coal-fired power station, Technical Review-. Mitsubishi heavy industries, 44, 2.

Infraline Energy Research and Information Services, 2006. GAIL-Infraline Natural Gas in India: 2006,

GAIL India Limited.

IPCC, 2005. IPCC special report on carbon dioxide capture and storage, prepared by Working Group III of the Intergovernmental Panel on Climate Change, Cambridge University Press.

Kapila, R.V., Chalmers, H., Leach, M., 2009. Investigating the prospects for Carbon Capture and Storage technology in India. Available at <http://www.sccs.org.uk/india-ccs-prospects.html>.

Koornneef, J., van Harmelen, T., van Horssen, A., van Gijlswijk, R., Ramirez, A., Faaij, A., Turkenburg, W., 2009. The impacts of $\mathrm{CO}_{2}$ capture on transboundary air pollution in the Netherlands. Energy Procedia, $1,3787-3794$.

Koornneef, J., Ramirez, A., van Harmelen, T., van Horssen, A., Turkenburg, W., Faaij, A., 2010. The impact of $\mathrm{CO}_{2}$ capture in the power and heat sector on the emission of $\mathrm{SO}$, NOx, Particulate matter, volatile organic compounds and NH3 in the European Union. Atmospheric Environment, 44, 1369-1385.

Koornneef, J., Ramirez, A., Turkenburg, W., Faaij, A., 2012. The environmental impact and risk assessment of $\mathrm{CO}_{2}$ capture, transport and storage $і$ i An evaluation of the knowledge base. Progress in Energy and Combustion Science, 38, 62-86. 
Krewitt, W., 2002. External costs of energy -do the answers match the questions? Looking back at 10 years of ExternE. Energy Policy, 30, 839-848.

Lvovsky, K., Hughes, G., Maddison, D., Ostro, B.D., Pearce, D., 2000. Environmental costs of fossil fuels: a rapid assessment method with application to six cities, World Bank.

Mallah, S., Bansal, N.K., 2010. Allocation of energy resources for power generation in India: business as usual and energy efficiency. Energy Policy, 38, 1059-1066.

Ministry of New and Renewable Energy. Available at: 〈http://www.mnre.gov.in/>.

Mondal, M.A.H., Denich, M., Vlek, P.L.G., 2010. The future choice of technologies and co-benefits of CO2 emission reduction in Bangladesh power sector. Energy, 35, 4902-4909.

Murata, A., Endo, E., 2010. Assessment of CDM activities by a generation planning model of the Chinese power grids. Journal of Energy and Power Engineering, 4, 1-14.

Nemet, G.F., Holloway, T., Meier, P., 2010. Implications of incorporating air-quality co-benefits into climate change policymaking. Environ Res Lett, 5, 014007.

Pittela, K., Rübbelkeb, D., 2008. Climate policy and ancillary benefits: A survey and integration into the modelling of international negotiations on climate change. Ecological Economics, 68, 210-220.

Ramanathan, K., Abeygunawardena, P., 2007. Hydropower development in India: a sector assessment, Asian Development Bank.

Roman, M., 2011. Carbon capture and storage in developing countries: A comparison of Brazil, South Africa and India. Global environmental Change, 21, 391-401. 
Shackley, S., Verma, P., 2008. Tackling CO2 reduction in India through use of CO2 capture and storage

(CCS): Prospects and challenges. Energy Policy, 36, 3554-3561.

Shrestha, R.M., Pradhan, S., 2010. Co-benefits of CO2 emission reduction in a developing country.

Energy Policy, 38, 2586-2597.

Shukla, P.R., Dhar, S., Victor, D.G., Jackson, M., 2009. Assessment of demand for natural gas from the electricity sector in India. Energy Policy, 37, 3520-3534.

Southern regional power committee, 2007. Annual report 2006-2007, CEA.

TERI, 2006. National energy map for India. Technology vision 2030, PSA/2006/3, The Energy Research Institute.

Tzimas, E., Mercier, A., Cormos, C.C., Peteves, S.D., 2007. Trade-off in emissions of acid gas pollutants and of carbon dioxide in fossil fuel power plants with carbon capture. Energy Policy, 35, 3991-3998.

UNFCCC, Clean Development Mechanism (CDM). Available at http://cdm.unfccc.int/.

Zhang, D., Liu,P., Ma, L., Zhang, L. and Ni, W., 2012a. A multi-period modelling and optimization approach to the planning of Chinâs power sector with consideration of carbon dioxide mitigation, Computers and Chemical Engineering, 37, 227-247.

Zhang, D., Ma, L., Liu,P., Zhang, L. and Li, Z., 2012b. A multi-period superstructure optimisation model for the optimal planning of Chinâ̂ power sector considering carbon dioxide mitigation Discussion on China@̂ carbon mitigation policy based on the model, Energy Policy, 41, 173-183. 
